\title{
INTERNATIONAL COMPETITION, SLIM FIRMS AND WAGE INEQUALITY
}

\author{
KLAUS WAELDE \\ PIA WEISS
}

CESIFO WORKING PAPER No. 1254

CATEGORY 7: TRADE POLICY

August 2004 


\title{
INTERNATIONAL COMPETITION, SLIM FIRMS AND WAGE INEQUALITY
}

\begin{abstract}
A country with Cournot competition and free entry experiences an increase of its market size either due to economic growth or international integration of goods markets. The implied increase in competition leads to shrinking mark-ups and forces firms to reduce overhead costs relative to output. This implies a reallocation at the aggregate level from administrative to productive activities. Relative factor rewards change and wage inequality increases. The factor losing in relative terms can even lose in real terms. From a quantitative perspective, international competition is shown to be the more plausible cause of rising wage inequality.
\end{abstract}

JEL Code: F12, J31.

Keywords: international trade, wage inequality, foreign competition, free entry and exit.

\author{
Klaus Waelde \\ Department of Economics \\ University of Dresden \\ 01062 Dresden \\ Germany \\ klaus@waelde.com
}

\author{
Pia Weiss \\ Technische Universität Chemnitz \\ Fakultät für Wirtschaftswissenschaften \\ Reichenhainer Str. 39 \\ 09111 Chemnitz \\ Germany
}

We would like to thank Henrik Horn, Michael Pflüger and Peter Neary for discussions and comments. The usual disclaimer applies. 


\section{Introduction}

The increase in wage inequality especially in the U.S. is a well-documented fact (e.g. Katz and Autor, 1999). This increase can be split into increases within and between groups, defined e.g. by age, education, experience and other observable characteristics. Almost three quarters of the overall increase in wage inequality can be attributed to increases within groups.

Most theoretical explanations have been suggested for increases between groups. Biased technological change and international trade are the most commonly suggested causes (for reviews, cf. e.g. Acemoglu, 2002 and Johnson and Stafford, 1999). The reorganization of production processes (Lindbeck and Snower 1996; Caroli and van Reenen, 2001) or education systems (Wälde, 2000) are also sometimes invoked as the primary reason. Some authors have also suggested explanations for the rise in wage inequality within groups. Most of them try to understand how technological change can be at the basis of relative wage changes (e.g. Galor and Moav, 2000; Aghion, 2002).

This paper is concerned with rises in wage inequality within groups, given that this is the quantitatively more important source. It is part of a literature (cf. e.g. Neary, 2002, or the short overview by Feenstra, 2001) that resuscitates international trade as a potential explanation for rising wage inequality, reacting to the tendency that the trade channel became less popular in recent years (e.g. Krugman, 2000). Mechanisms based on the Stolper-Samuelson theorem or on implicit strong labour supply increases are not regarded as empirically very relevant as relative prices did not change sufficiently much and the factor content of trade is not sufficiently large.

We present a mechanism where neither changes in terms of trade nor international factor flows are required and nevertheless (the potential of) international trade causes rising wage inequality. We propose a simple model where many firms interact in an imperfectly competitive market and where an increase in the degree of competition requires firms to become "slimmer". It is then shown how becoming slimmer and rising wage inequality is related.

In our static setup, the degree of competition among firms is captured by a markup of prices over marginal cost. Assuming Cournot competition between firms, the number of competitors active in a market determines the degree of market power an individual firm has. Allowing for free entry and exit, the number of firms and thereby the markup are endogenous. When the number of firms rises, e.g. because the economy's resource base increases due to growth or because it opens up for trade, competition rises and markups of firms shrink. If a firms wants to stay in the market despite lower markups and implied lower operating profits, it needs to reduce overhead costs per 
unit of output. This reorganization at the firm level induces factor flows at the aggregate level from administrative activities to production.

A consequence of reallocating factors of production are changes in relative and absolute wages. Factors of production that are more intensively used in production gain from reallocation and factors of production less intensively used lose from reallocation. In the model presented here, no changes in international goods prices and no increase in the volume of trade is required to understand wage changes.

The paper also shows that this channel can be of quantitative importance. Calibrating the model will show that a sufficiently large reduction in the market power of firms can indeed account for up to $100 \%$ of the increase in wage inequality within groups. As a reduction in endogenous market power is fundamentally caused by changes in the size of an economy as measured by its factor endowment, accounting for this increase requires an increase of the economy by a factor of around 9 . While such an increase can only partly be explained by economic growth (GDP in the US increased by a factor of 2.8 from 1963 to 1995), it becomes much more plausible when thinking of integrating the US into a world economy (the active workforce in OECD countries in 1995 is more than 6 times larger than the workforce of the US in 1963). The paper therefore concludes that integration in the world economy is the more plausible driving force behind lean production and implied changes in the wage structure than economic growth. It is also shown how the implied reductions in market power relate to estimates in the literature on markups by industry.

The mechanism is of interest also from a purely trade-theoretical perspective. Many economists believe (summarized e.g. by Bhagwati, 1994, or Markusen et al., 1995, ch. 11) that more competition resulting from international trade benefits the economy as a whole or even all factors of production. This is sometimes referred to as the lifting all boats effect. We show that more competition per se is beneficial for all factors of production indeed but the reallocation effects caused by more competition can lead to distributional effects including real losses for certain factors of production.

Clearly, the mechanism whereby international integration leads to more competition is well-understood from other models with Cournot competition (Dixit, 1984; Venables, 1985; Eaton and Grossman, 1986; Ruffin, 2003). ${ }^{3}$ Distributional effects have not been studied in these models, however, as usually only one factor of production is used.

\footnotetext{
${ }^{3}$ This result can also be obtained in a Dixit-Stiglitz-type imperfect competition setup. See e.g. Flam and Helpman's (1987) analysis of industrial policy in a two-country world.
} 


\section{The model}

\subsection{A closed economy}

The economy is endowed with a fixed amount of highly-skilled individuals $H$ and less-skilled individuals $L$, also called labour. Production of the homogeneous consumption good $X$ requires a production process and administration services. Production can take place only under administrative guidance. Administration requires both skilled individuals $h_{m}$ and labour $l_{m}$ and is provided under constant returns to scale,

$$
m=m\left(h_{m}, l_{m}\right),
$$

with $m($.$) having standard neoclassical properties. Administrative services$ can be provided either in-house or bought on the market. In the former case, each firm minimizes the costs associated with the provision of $m$. Assuming perfect competition in the administration sector for the latter case, both interpretations are formally equivalent. In either case, the price $p_{m}$ equals unit costs,

$$
p_{m}=a_{l m} w_{L}+a_{h m} w_{H},
$$

where $a_{l m}$ and $a_{h m}$ indicate the amount of less-skilled and skilled workers used to produce one unit of administrative services and $w_{L}$ and $w_{H}$ are the respective factor rewards.

The amount of administration services required for production in each firm is fixed at $\bar{m}$. Hence, output $\tilde{x}$ of a representative firm is given by

$$
\tilde{x}=\left\{\begin{array}{cl}
0 & \text { if } m<\bar{m} \\
x\left(h_{x}, l_{x}\right) & \text { if } \quad m \geq \bar{m}
\end{array}\right.
$$

where $x($.$) has standard neoclassical properties with constant returns as well$ and skilled and less-skilled labour employed for production are denoted by $h_{x}$ and $l_{x}$, respectively. Optimal behavior implies $m=\bar{m} .^{4}$

Total output is given by the sum of output $x$ of all $n$ firms in the market, $X=n x .^{5} \quad$ As firms behave as Cournot competitors, the price $p_{x}$ of the consumption good is given by

$$
p_{x}=\mu\left[a_{l x} w_{L}+a_{h x} w_{H}\right], \quad \text { with } \mu=\frac{n}{n-1}>1,
$$

\footnotetext{
${ }^{4}$ The existence of a fixed input requirement for administrative services is comparable to fixed costs. If factor rewards were constant (which they are not), a fixed requirement for administrative services would be identical to fixed costs of production. Here, the price for management services $p_{m}$ and, therefore, the associated costs $p_{m} \bar{m}$ may respond to parameter changes. Fixed costs would not.

${ }^{5} \mathrm{We}$ anticipate the fact that all firms will have the same size as they all face identical marginal costs.
} 
where unit input factors for factor $i$ are given by $a_{i x}$ and the parameter $\mu$ denotes the markup over the unit costs in squared brackets.

We assume throughout that the skill intensity $\rho_{x}$ is higher in the production unit of the firm than in the administration unit,

$$
\rho_{x} \equiv \frac{a_{h x}}{a_{l x}}>\frac{a_{h m}}{a_{l m}} \equiv \rho_{m} .
$$

This assumption will be crucial for our results. When thinking of labour groups as observationally distinct, various examples can be thought of: in industries that are low-skill intensive (e.g. mining, construction, some manufacturing activities), the administration unit includes management and production should be less skill intensive. Consulting firms or the education sector, however, can plausibly be considered to have a more skill intensive production unit. With our focus on observationally equivalent factors of production, the assumption in (5) is much more convincing: in the scenario we analyze, factors of production will move out of administrative activities into the production units. Workers therefore have to adapt to new job descriptions. Those who move will be the more agile ones and the more highly skilled will be concentrated in production units. Alternatively, one can stress that a production process and contact with customers requires more flexibility than certain repetitive administrative activities. ${ }^{6}$

With free entry, profits are driven to zero, so that $p_{x} x=\left(a_{l x} w_{L}+\right.$ $\left.a_{h x} w_{H}\right) x+p_{m} \bar{m}$. Using the pricing equation (4), the zero profit condition requires the equality between operating profits (defined as the difference between revenues and variable production costs) and administration costs,

$$
\frac{p_{x} x}{n}=p_{m} \bar{m}
$$

A factor market equilibrium requires the equality of labour supply $L$ and labour demand in production, $a_{l x} n x$, and for administration, $a_{l m} n \bar{m}$. With an identical equation for skilled individuals, we obtain

$$
\begin{aligned}
L & =a_{l x} n x+a_{l m} n \bar{m}, \\
H & =a_{h x} n x+a_{h m} n \bar{m} .
\end{aligned}
$$

The system of equations (2), (4) and (6) - (8) characterizes the equilibrium of the economy. We chose administration services as numeraire and normalize $p_{m}$ to unity. These equations specify the values for the factor prices $\left(w_{L}, w_{H}\right)$, the product price $p_{x}$, the number $n$ of firms and the output $x$ of an individual firm as a function of the exogenously given factor endowments $H$ and $L$.

\footnotetext{
${ }^{6}$ Unfortunately, we did not find any data on skill intensities within various departments of a firm. Information on e.g. occupation is always for a firm as a whole. If this information was available, one could apply this approach also to between group inequality.
} 


\subsection{Modelling international integration}

We view international integration, economic growth or both as the driving force behind leaner production and changes in wage inequality. Both international integration and growth can be captured in a simple way by an increase in factor endowments of the economy. When economic growth is labour saving and the same for both technologies $x$ and $m$, growth is identical to an increase in factor endowment. When growth stems from increases in workers' productivity due to human capital accumulation or learning by doing, this is again formally identical to an increase in factor endowment. While a fully dynamic model would be more complete, we believe that our main results are robust to this extension.

When integration in international goods markets in considered, this can again be captured by increases in the resource base. Imagine that an economy opens up to world markets where other countries are characterized by the same relative endowment $H / L$, i.e. a situation where integration takes place e.g. among equally industrialized economies. (Section 7 shows that the main point holds in more general cases as well.) The fundamental effect integration has is to embed the formerly autarcic economy in a world economy that has a larger factor endowment of $H$ and $L$ but the same ratio $H / L$. Hence, integration is identical to a equi-proportional increase of $H$ and $L$.

\subsection{Deriving the reduced form}

All results concerning lean production, reallocation of factors of production and changes in the wage structure are therefore derived by analyzing a closed economy where the factor endowment $H$ and $L$ changes proportionally, while keeping the ratio

$$
\kappa \equiv H / L
$$

constant. ${ }^{7}$ We can use the same approach as Jones (1965), despite the presence of imperfect competition features in our model. We also study proportional changes of endogenous variables as a function of proportional changes of exogenous ones. In our case, the following set of equations (derived in appendix 8.1) determines the proportional changes of $x, n, w_{L}, w_{H}, p_{x}$ as functions of the proportional change in the market size $s$. Proportional changes

\footnotetext{
${ }^{7}$ We need factor price equalisation (FPE) in order to be able to represent integration in a world economy by an expansion of factor endowments of a closed economy. FPE is present if either countries are symmetric or countries are not too asymmetric and firms can outsource their administrative activities such that they are tradeable. FPE in the latter case then follows from (2) and (4).
} 
are denoted by a hat ${ }^{\prime}$, , i.e. $\hat{z}=d z / z$ and exogenous changes in endowments are denoted by $\hat{L}=\hat{s}$ and $\hat{H}=\hat{\kappa}+\hat{s}$, where $\hat{\kappa}=0$ in the main part of the paper, as discussed above.

$$
\begin{aligned}
\hat{p}_{x}-\left(\theta_{l x} \hat{a}_{l x}+\theta_{h x} \hat{a}_{h x}\right) & =\theta_{l x} \hat{w}_{L}+\theta_{h x} \hat{w}_{H}+\hat{\mu}, \quad \hat{\mu}=-\frac{\hat{n}}{n-1} \\
-\left(\theta_{l m} \hat{a}_{l m}+\theta_{h m} \hat{a}_{h m}\right) & =\theta_{l m} \hat{w}_{L}+\theta_{h m} \hat{w}_{H} \\
\hat{p}_{x} & =\hat{n}-\hat{x} \\
\hat{s}-\left(\lambda_{l x} \hat{a}_{l x}+\lambda_{l m} \hat{a}_{l m}\right) & =\lambda_{l x} \hat{x}+\hat{n} \\
\hat{\kappa}+\hat{s}-\left(\lambda_{h x} \hat{a}_{h x}+\lambda_{h m} \hat{a}_{h m}\right) & =\lambda_{h x} \hat{x}+\hat{n}
\end{aligned}
$$

The coefficient $\lambda_{i j}$ stands for the fraction of the factor $i$ used in the production of good $j$ (cf. appendix, equation (28)). As factors are fully employed, fractions add to unity, i.e. $\lambda_{i x}+\lambda_{i m}=1, i=l, h$. The coefficient $\theta_{i j}$ denotes the share of value added (adjusted for markups) ${ }^{8}$ going to factor $i$ in activity $j$ (cf. appendix, equation (32)). Accordingly, the shares of both factors add to unity, i.e. $\theta_{l j}+\theta_{h j}=1, j=x, m$.

Equations (10) and (11) describe how prices and wages respond to parameter changes. For the oligopolistic production of the consumption good (10), changes in factor rewards are accommodated by changes in the price $p_{x}$, in technologies (the term in brackets on the left-hand side) and by changes in the markup. The definition of the markup in (4) implies that its proportional change is given by $\hat{\mu}=-\hat{n} /(n-1)$. For administrative activities, equation (11) illustrates that changes in the factor prices are balanced by adjustments in technologies only. The price $p_{m}$ for administration services cannot adjust, as it was chosen as numeraire.

Equation (12) stems from the zero profit condition (6). As the price for administration services was set to unity and a fixed amount of administration services is required, it simply says that zero profits prevail only if the operating profits from sales of the consumption good remain constant (in nominal terms) ${ }^{9}$

Equations (13) and (14) describe equilibrium changes on the factor market. An equi-proportional increase $\hat{s}$ in the market size is accommodated by changes in the technology (the term in the brackets on the left-hand side) and changes in the supply (the right-hand side). As the demand of a single firm for administration services is fixed, supply can only vary when either output $x$ of the representative firm or the number $n$ of firms change. Since the factor shares of both activities add to one, $\hat{n}$ is not weighted.

\footnotetext{
${ }^{8}$ This adjustment allows us to use this very convenient approach despite imperfect competition in our setup which contrasts the perfect competition analysis of Jones (1965).

${ }^{9}$ We will see below that profits will need to change in terms of the consumption good.
} 
Equations (10)-(14) can be simplified. As both oligopolistic consumption good firms and perfectly competitive administration firms minimize production costs and are price takers on the factor markets, we obtain

$$
\theta_{l j} \hat{a}_{l j}+\theta_{h j} \hat{a}_{h j}=0, \quad j=x, m
$$

for both types of activities (cf. appendix 8.1.2). Firms produce at minimum costs when the cost of an additional unit of labour is exactly offset by marginally reducing the amount of skilled individuals. This condition simplifies the pricing equations (10) and (11) as the brackets on the left-hand side disappear.

The zero profit condition (12) can be used in equation (10). Subtracting equation (11) from the resulting condition yields

$$
\hat{x}-\mu \hat{n}+|\theta|\left(\hat{w}_{L}-\hat{w}_{H}\right)=0,
$$

where $|\theta|$ is the determinant of the factor share matrix $\theta$ (cf. appendix, equation (35)). Equation (34) in the appendix shows that the determinant $|\theta|$ is negative if the technology for producing the consumption good is skill intensive relative to the technology for administration services (as we assume). This equation is the first one to be used in the reduced form.

With linear homogenous production functions and perfect competition on factor markets, the elasticity of substitution between the factors of production in activity $j$ can be written as $\sigma_{j}=\left(\hat{a}_{h j}-\hat{a}_{l j}\right) /\left(\hat{w}_{L}-\hat{w}_{H}\right)$. Together with the appropriate equation from (15), we obtain (cf. appendix 8.1.3)

$$
\begin{aligned}
\lambda_{l x} \hat{a}_{l x}+\lambda_{l m} \hat{a}_{l m} & =\delta_{l}\left(\hat{w}_{L}-\hat{w}_{H}\right), \\
\lambda_{h x} \hat{a}_{h x}+\lambda_{h m} \hat{a}_{h m} & =-\delta_{h}\left(\hat{w}_{L}-\hat{w}_{H}\right),
\end{aligned}
$$

where

$$
\delta_{l} \equiv \lambda_{l x} \theta_{h x} \sigma_{x}+\lambda_{l m} \theta_{h m} \sigma_{m}, \quad \delta_{h} \equiv \lambda_{h x} \theta_{l x} \sigma_{x}+\lambda_{h m} \theta_{l m} \sigma_{m}
$$

These equations can be used to replace changes in technology in factor market conditions (13) and (14) by changes in relative factor rewards. This yields

$$
\begin{aligned}
\lambda_{l x} \hat{x}+\hat{n}-\delta_{l}\left(\hat{w}_{L}-\hat{w}_{H}\right) & =\hat{s} \\
\lambda_{h x} \hat{x}+\hat{n}+\delta_{h}\left(\hat{w}_{L}-\hat{w}_{H}\right) & =\hat{s}+\hat{\kappa}
\end{aligned}
$$

Together with equation (16), the modified factor market equilibrium conditions (20) and (21) constitute a system of equations which determines the effect of changes in the exogenous variable $s$, i.e. the effect of an increase 
in the resource base, on the endogenous variables $\left(n, x, w_{L} / w_{H}\right)$. For later purposes, we summarize these equations as

$$
\begin{gathered}
J b=d \text { with } \\
J=\left[\begin{array}{ccc}
\lambda_{l x} & 1 & -\delta_{l} \\
\lambda_{h x} & 1 & \delta_{h} \\
1 & -\mu & |\theta|
\end{array}\right], \quad b=\left[\begin{array}{c}
\hat{x} \\
\hat{n} \\
\hat{w}_{L}-\hat{w}_{H}
\end{array}\right], \quad d=\left[\begin{array}{c}
\hat{s} \\
\hat{s}+\hat{\kappa} \\
0
\end{array}\right]
\end{gathered}
$$

\section{Aggregate effects of an increasing resource base}

The first question to be answered is whether the number of firms grows proportionally or under-proportionally when countries grow or integrate, i.e. when $s$ increases. In the former case, no exit of firms would take place: With an integration scenario in mind, the number of firms in the integration equilibrium is just the sum of the number of firms in the countries' autarky state. In the latter case the world-wide number of firms in a trading situation is lower than the sum of the number of firms in autarky - international integration implies exit of firms.

Proposition 1 The number of firms rises under-proportionally if the market size s increases, i.e.

$$
\hat{s}>0 \Rightarrow 0<\hat{n}<\hat{s} .
$$

Proof. Define $j_{1} \equiv|\theta||\lambda|, j_{2} \equiv \delta_{l}+\delta_{h}$ and $j_{3} \equiv \mu\left[\delta_{l} \lambda_{h x}+\delta_{h} \lambda_{l x}\right]$. This definition directly implies $j_{2}, j_{3}>0$. From (30) and (34) $j_{1}>0$ as well. Using (31), the determinant of the Jacobi matrix in (22) can be written as

$$
|J|=j_{1}+j_{2}+j_{3}>0
$$

and the second element of adj $J d$ is $\hat{s}\left(j_{1}+j_{2}\right) \equiv J_{n} \hat{s}$. Hence, $\hat{n}=\hat{s}\left(j_{1}+\right.$ $\left.j_{2}\right) /|J|$. As $j_{1}+j_{2}<|J|$, it follows that $0<\hat{n}<\hat{s}$ if $\hat{s}>0$.

This proposition can be illustrated for a trade scenario as follows: immediately after economies have removed prohibitive trade barriers, there would be $\sum n_{c}^{a}$ firms in the market, where $n_{c}^{a}$ is the number of firms in autarky in country $c$. Proposition 1 indicates that this situation is not sustainable in the long run. The adjustment process is therefore characterized by an reduction of the number of firms. The reason for firm exit is that immediately after opening up to trade, firms make losses: The markup $\mu$ in (4) reduces due to the increased number of competitors while cost of administrative services at pre-integration output can not be covered. Firms therefore leave the market until the zero profit condition holds again. 
Proposition 2 The output $x$ of a firm increases with the market size s, i.e.

$$
\hat{s}>0 \Rightarrow \hat{x}>0 \text {. }
$$

Proof. From (22), $\hat{x}=\hat{s} \mu j_{2} /|J|$. As $|J|>0$ from (23), it follows that $\hat{x}>0$ if $\hat{s}>0$.

The zero profit condition is restored at a lower markup by an expansion of output per firm. With constant fixed costs resulting from the required fixed input $\bar{m}$ of administrative services, firms need to produce more in order earn the same amount of the operating profits that allow to cover these fixed costs, i.e. $\hat{x}>0$

The previous two propositions can be combined to obtain

Proposition 3 The output of the consumption good increases over-proportionally as the market size rises, i.e.

$$
\hat{s}>0 \Rightarrow \hat{n}+\hat{x}>\hat{s} .
$$

Proof. Let $j_{1}, j_{2}, j_{3},|J|, J_{x}$ and $J_{n}$ be defined as above. Then, $\hat{n}+\hat{x}=$ $\hat{s}\left(J_{n}+J_{x}\right) /|J|$. As $\lambda_{h x}, \lambda_{l x}<1, \mu j_{2}>j_{3}$ so that $J_{n}+J_{x}>|J|$ and $\hat{n}+\hat{x}>\hat{s}$.

This effect can also be explained with increasing competition in the production of $x$. As in the integration scenario the world-wide number of oligopolistic firms reduces due to integration, there are fewer administrative jobs after integration. Factors of production therefore move from administrative to productive activities and total output increases. As competition rises in each country, this effect holds also for each country individually (each country produces more than before integration) and the increase in consumption good output $\hat{n}+\hat{x}$ must be larger than the increase $\hat{s}$ in the market size.

For the international integration scenario, this proposition implies

Corollary 1 There are gains from trade.

Proof. For monotonous utility functions, social welfare $u$ is an increasing function of output $X$ of the consumption good normalized by country size $s, u=u(X / s), u^{\prime}(\cdot)>0$. As $\hat{n}+\hat{x}-\hat{s}>0$ by the last proposition, $X / s$ increases as country size increases. Welfare $u$ therefore rises when countries integrate. 


\section{Distributional effects of an expanding re- source base}

\subsection{General results}

We now study the effects of a rising resource base for relative factor rewards.

Proposition 4 At invariant relative factor endowment, human capital rewards $w_{H}$ rise relative to wages $w_{L}$ following an increase in the market size $s$, whenever the production of the consumption good is more skill intensive than production of administration services, i.e.

$$
\hat{s}>0 \quad \text { and } \quad \rho_{x}\left\{\begin{array}{l}
> \\
<
\end{array}\right\} \rho_{m} \Rightarrow \hat{w}_{H}-\hat{w}_{L}\left\{\begin{array}{l}
> \\
<
\end{array}\right\} 0 .
$$

Proof. Let the determinant of the Jacobi matrix be defined as above. The third element of adj $J d$ is $\hat{s} \mu|\lambda|$ so that $\hat{w}_{H}-\hat{w}_{L}=-\hat{s} \mu|\lambda| /|J|$. Then, the proposition follows directly from equation (30).

The intuition behind this proposition is similar to the intuition behind the Stolper-Samuelson theorem. Continue to assume that production is skill intensive relative to administration. When relative output of administrative services declines due to an increase of the economy, the proportion of lessskilled relative to skilled labour that becomes available is, at given relative factor prices, higher than the proportion that production is willing to absorb. Full employment can therefore only be restored if firms (in all sectors) or departments (for both activities) substitute less-skilled by skilled individuals. The latter takes place only if factor rewards for labour decrease relatively to factor rewards for the skilled.

While these relative changes are important, absolute changes allow a better prediction of changes in individual welfare. For real factor rewards we have

Proposition 5 The factor of production that gains relative to the other factor also gains in real terms,

$$
\hat{w}_{H}-\hat{w}_{L}\left\{\begin{array}{l}
> \\
<
\end{array}\right\} 0 \Rightarrow\left\{\begin{array}{l}
\hat{w}_{H} \\
\hat{w}_{L}
\end{array}\right\}-\hat{p}_{x}>0 .
$$

Proof. The proof holds for the case where skilled workers gain relatively to labour, $\hat{w}_{H}-\hat{w}_{L}>0$. Subtracting equation (10) from $\hat{w}_{H}$ and noting that the bracket term on the left-hand side vanishes gives $\hat{w}_{H}-\hat{p}_{x}=\theta_{l x}\left(\hat{w}_{H}-\right.$ 
$\left.\hat{w}_{L}\right)+\hat{n} /(n-1)$. Both terms on the right-hand side are positive. The proof for the opposite case where $\hat{w}_{H}-\hat{w}_{L}<0$ follows equivalent steps.

Surprisingly, a relative decline of wages does not necessarily (as in the Stolper-Samuelson theorem for the perfect competition model) imply a decline of wages in terms of the consumption good:

Proposition 6 The factor of production that loses relative to the other factor gains in real terms if the price reduction effect from more competition is stronger than the wage reduction effect coming from reallocation,

$$
\hat{w}_{L}-\hat{p}_{x}\left\{\begin{array}{l}
> \\
<
\end{array}\right\} 0 \Leftrightarrow-\theta_{h x}\left(\hat{w}_{H}-\hat{w}_{L}\right)+\frac{1}{n-1} \hat{n}\left\{\begin{array}{l}
> \\
<
\end{array}\right\} 0 .
$$

Proof. Solving equation (10) for $\hat{w}_{L}-\hat{p}_{x}$, taking (15) and (33) into account, gives

$$
\hat{w}_{L}-\hat{p}_{x}=-\theta_{h x}\left(\hat{w}_{H}-\hat{w}_{L}\right)+\frac{1}{n-1} \hat{n} .
$$

Equation (24) nicely reveals the intuition behind propositions 5 and 6 : Changes in real factor rewards depend on changes in relative factor rewards caused by factor reallocation, as captured by the first term on the right-hand side, and on changes in the number of firms in the economy, the second term on the right-hand side of the equation. An increase of this second term represents an increase in competition and thereby a reduction in the distortion on the final good market. As economic growth or international integration increases the number of competitors, this second term stands for the reduction of the markup which implies, ceteris paribus, lower profits and therefore a larger share of output going to factors of production implying higher real factor rewards.

Real rewards for skilled workers therefore increase as both the relative change in factor rewards (i.e. the reallocation from administration to production) and the increase in competition imply higher rewards for skill. Real wages for unskilled workers decrease as in the perfect competition model if the beneficial effect from more competition is weak. Real wages increase if the competition effect outweighs the loss implied by the reallocation to production activities.

This discussion directly implies the following

Corollary 2 (a) If a country characterized by a strong domestic inefficiency (few domestic firms and high markups) integrates, there are gains from integration and both factors of production gain in real terms.

(b) If a country with low markups starts trading, skilled workers profit and less-skilled workers lose in real terms. 
Proposition 6 is important also because it formalizes and partially contradicts an argument dear to many trade economists. Rising competition by opening up to trade is beneficial for all factors of production as it reduces domestic inefficiencies. This is referred to as "lifting all boats" by e.g. Bhagwati (1994). Our setup shows that this is not necessarily the case. In fact, rising international competition is the source of more wage inequality by proposition 5 and can even lead by proposition 6 to a drop in real wages of the less favoured factor of production.

\subsection{Cobb-Douglas and CES economies}

Equation (24) provides intuition for potential negative distributional effects of international competition. This expression by itself, however, does not provide information on whether the positive effect of stronger competition (the second term) might not actually always overcompensate the negative effect for low-skilled resulting from reallocation (the first term). This section therefore studies a Cobb-Douglas and a CES economy for which more precise results are available.

In a Cobb-Douglas version of the economy presented above, technologies in (1) and (3) are given by $m\left(h_{m}, l_{m}\right)=h_{m}^{\beta} l_{m}^{1-\beta}$ and $x\left(h_{x}, l_{x}\right)=h_{x}^{\alpha} l_{x}^{1-\alpha}$, where $\alpha>\beta$. Going through similar steps as for deriving proposition 6 gives

Theorem 7 In a Cobb-Douglas economy, both factors gain in real terms.

Proof. cf. appendix 8.2

In the Cobb-Douglas case, more international competition "lifts all boats" indeed: International integration always reduces the inefficiency of imperfect competition sufficiently much. In this Cobb-Douglas case, part (a) of corollary 2 holds and factors of production in each country gain from integration.

In a CES specification, technologies are

$$
\begin{aligned}
& m\left(h_{m}, l_{m}\right)=\left(\beta h_{m}^{(\varepsilon-1) / \varepsilon}+(1-\beta) l_{m}^{(\varepsilon-1) / \varepsilon}\right)^{\varepsilon /(\varepsilon-1)}, \\
& x\left(h_{x}, l_{x}\right)=\left(\alpha h_{x}^{(\varepsilon-1) / \varepsilon}+(1-\alpha) l_{x}^{(\varepsilon-1) / \varepsilon}\right)^{\varepsilon /(\varepsilon-1)} .
\end{aligned}
$$

We assume identical elasticities of substitutions across activities as this guarantees a more skill intensive production activity, as long as $\alpha>\beta$. Unfortunately, no analytical results more specific than (24) can be obtained. A numerical solution, however, shows that for a large parameter set real wages for low-skilled increase while for other parameters, real wages drop. ${ }^{10}$ Hence,

\footnotetext{
${ }^{10}$ All numerical solutions were computed in Mathematica. The programmes are available upon request. For a typical choice of parameters that leads to an increase of all real wages, cf. table 1 below. When the $\mathrm{H} / \mathrm{L}$ ratio is higher, real wages of labour drop.
} 
Numerical result 1 In a CES economy, international competition can lead to "lifting all boats" or to the traditional Stolper-Samuelson effect, even though terms of trade are constant and (implied) factor flows are zero.

Whatever the choice of parameters, intuition for the result always goes back to equation (24). Any parameter change that implies more competition in autarky and a lower growth of numbers of competitors when the economy opens up leads to less strong gains from integration due to a reduced distortion. As a consequence, the factor experiencing a loss in demand due to relocation of economic activity from administration to production and lower wages tends to lose from more international competition. Part (b) of corollary 2 would therefore be the relevant finding.

\section{$5 \quad$ Wage inequality and trade}

Even though the discussion so far often referred to international trade, the fundamental driving force has been an increase in factor endowment. This increase can result both from economic growth and international integration. This section will therefore use a numerical solution of the CES specification (25) in order to compute by how much the resource base needs to increase in order to explain a sufficiently large increase in wage inequality. By doing so, international integration turns out to be the more plausible source for a rise in wage inequality through the channel presented here than economic growth.

\subsection{Calibration}

The variance of log weekly wages of full-time, full-year (male and female) workers increased in the United States from .25 in 1963 to .36 in 1995 i.e. by .11 (Katz and Autor, 1999, Tables 1 and 5). One-quarter of this change can be attributed to changes between groups, three-quarters are changes within groups, i.e. due to unobserved factors different from education, experience etc. When wage inequality is measured by the $90 / 10$ log weekly wage differential, inequality increased for male workers from roughly 1.2 to roughly 1.55 within the same period (Katz and Autor, 1999, Figure 4), i.e. wage income of the 90th percentile worker was 3.3 times wage income of the 10th percentile worker in 1963 and 4.7 times in 1995.

Can the mechanism presented above account for this increase? Looking at the structure of the CES version of the model shows that the model can be calibrated to reflect the situation in 1963 with $100 \%$ precision. Equilibrium 
can be described by a free-entry condition and two labor market clearing conditions (cf. appendix 8.3),

$$
\begin{gathered}
\left(\frac{a_{l x}}{a_{l m}}\right)^{1 / \varepsilon} \frac{1}{n-1} \frac{x}{\bar{m}}=\frac{1-\alpha}{1-\beta}, \\
\frac{L}{\bar{m} n}=a_{l x} \frac{x}{\bar{m}}+a_{l m}, \quad L \frac{H / L}{\bar{m} n}=a_{h x} \frac{x}{\bar{m}}+a_{h m},
\end{gathered}
$$

where $a_{i j}$ are the CES versions of unit demand functions. These three equations determine the endogenous variables $\frac{x}{\bar{m}}, n$ and $\omega \equiv w_{L} / w_{H}$. If we want a certain relative wage to be the equilibrium wage, we fix all parameter values and modify $H / L$ to obtain the desired relative wage. By modifying also $L$, a reasonable degree of competition, i.e. at reasonable mark-up, can be obtained. The number $n$ of firms should thereby not be seen as the number of independent firms in some actual economy but rather as the certain degree of competition. A more realistic modelling would imply many sectors and certain demand elasticities (which equal unity here). The following table gives an overview of parameters for the 1963 calibration.

\begin{tabular}{ccc|cc|cll}
\multicolumn{4}{c|}{ exogenous } & imposed & & \multicolumn{3}{|c}{ computed } & \\
\hline \hline$\alpha$ & $\beta$ & $\varepsilon$ & $w_{L} / w_{H}$ & $\mu$ & $H / \bar{m}$ & $L / \bar{m}$ & $x / \bar{m}$ \\
.7 & .3 & 5 & $1 / 3.3$ & 3 & .1 & 3.1 & .2
\end{tabular}

Table 1: Parameter choices

We first set the elasticity of substitution at some sufficiently high value, say $\varepsilon=5$, to capture inequality within groups where factors are good substitutes and perform very similar jobs. Parameters for technologies in (25) are chosen symmetric around .5 such that a shift towards production implies higher demand for skilled, i.e. $\alpha>\beta$. In order to obtain the 1963 90/10 wage ratio, $\omega$ is set equal to $1 / 3.3$, corresponding to the stylized facts reported above. ${ }^{11}$ We further impose $\mu=3$ which means that $2 / 3$ of revenue is used to pay fixed costs and $1 / 3$ is used to cover variable cost.

The implied values for $H / \bar{m}$ and $L / \bar{m}$, i.e. factor endowments which would give the imposed values of $\omega$ and $\mu$ as equilibrium outcomes are .1 and 3.1. In efficiency units there are 30 times more less-skilled than skilled. ${ }^{12}$

\footnotetext{
${ }^{11}$ Setting $\omega=1 / 3.3$ implicitly assumes that relative productivity $h$ of skilled to lessskilled is one. If some reasonable ratio $N_{H} / N_{L}$ of the number of skilled to unskilled workers should be reflected as well, one can choose relative productivity $h$ different from one to determine $H / L \equiv N_{H} h / N_{L}$. The relative observed wage would then be $w_{L} /\left(h w_{H}\right)$.

${ }^{12}$ Again, this is a consequence of the assumption that $h=1$ and would be smaller with $h>1$.
} 
Output of a representative firm amounts to $x / \bar{m}=.2$. All this is relative to fixed management requirements (which could be chosen to match some other variable of interest).

\subsection{Trade or growth?}

We then increase $H$ and $L$ equi-proportionally, representing an integration into a world economy with the same high-skill to skill ratio. Focusing on relative wages, we get the following picture.

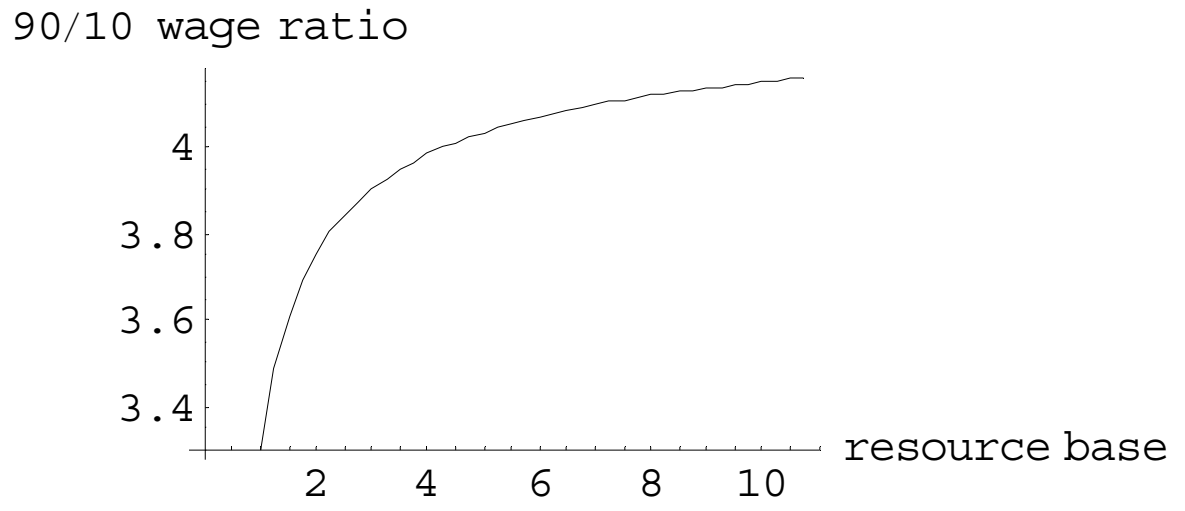

Figure 1: Relative wages under increasing international competition

The relative wage ratio in 1963, where the relative market size of the US is 1 (meaning that the country is in autarky), is 3.3. Over time, the relative market size, i.e. the market in which US firms are active, increases. Measuring the exact increase in the market size is very difficult and depends on the industry, growth in this industry and its openness. In terms of the model, the size is measured by the increase in factor endowments $H$ and $L$ from a country in autarky to factor endowments of all economies taken together in an integrated world economy. If we measure this endowment in 1963 by the active workforce of the US (approx. 67 million, full time equivalent) and endowment of the integrated world economy in 1995 by the active workforce of OECD countries (approx. 418 million), endowment increased from 67 to 418 by a factor of 6.2 . Real US GDP over this period increased by a factor 
of approx. 2.8. The total increase of the resource-base, i.e. the size of the market in the sense of the above model, therefore amounts to 9 .

Looking at figure 1 shows that the relative wage predicted by the model increases from 3.3 at a resource base of 1 to 4.1 after a 9-fold increase. The observed increase is from 3.3 to 4.7 . Taking into account that only three quarters are intended to be explained by the present model (as we focus on within group wage inequality), the observed increase that should be explained is from 3.3 to 4.35 . As this is $75 \%$ of the observed increase, the model is able to capture roughly the entire increase in within group wage inequality.

Recalling that the overall increase in the resource base by a factor of 9 splits into an increase due to international trade of 6.2 and only 2.8 due to growth, one can argue that, given this theoretical background, the overwhelming share of the increase in wage inequality within groups is accounted for by international trade. ${ }^{13}$

\subsection{Empirical evidence on markups}

Our mechanism to explain rising wage inequality depends centrally on the increase in competition. This increase is predicted to decrease the markup. In the calibration presented above, the markup shrinks from $\mu=3$ in 1963 to $\mu=1.36$ in 1995.

There is a considerable literature that provides estimates of the markup of prices over marginal cost. The literature started with Hall $(1988,1990)$ and was followed by Roeger (1995), Basu and Fernald (1995) and others. ${ }^{14}$ An overview of findings is given in table 2 .

\begin{tabular}{l|lll} 
& Hall 1988 & Roeger 1995 & $\begin{array}{l}\text { Basu and } \\
\text { Fernald 1995 }\end{array}$ \\
\hline \hline returns & 1 (imposed) & 1 (imposed) & $<1$ \\
markup $\mu$ & $2.06 ; 3.10$ & $1.45 ; 1.48$ & 1.15
\end{tabular}

Table 2: Markup estimates

Hall (1988) derived the specification for his regression equation under the assumption of constant returns to scale. Markup estimates were obtained for up to 26 industries and for industry groups. Estimates for durable goods

\footnotetext{
${ }^{13}$ Clearly, this does not rule out the relevance of explanations based on biased technological change or other mechanisms. An ultimative judgement would require a model that encompasses all these mechanisms. The main point here is to stress the importance international integration can have.

${ }^{14} \mathrm{~A}$ more recent analysis with further references is by Altug and Filiztekin (2002).
} 
and non-durable goods are 2.06 and 3.10, respectively. This is broadly in the range of the initial markup of $\mu=3$ we set above. Subsequently, estimates of markups became smaller as the upward bias in Hall's approach could be removed by also taking relationships for prices into account: Roeger (1995) finds values of 1.45 and 1.48 only. Basu and Fernald (1995) allow for nonconstant returns to scale and use output rather than value added data. They find decreasing returns to scale (cf. also Basu and Fernald, 1997) and a markup of 1.15, i.e. even lower than Roeger's results.

Given that none of these studies provides evidence on a possible time trend for markups, one could conclude that markups are basically constant (even though a cyclical movement of markups is well-documented; e.g. Altug and Filiztekin, 2002). This would mean that any explanation that builds on shrinking markups is not convincing.

One should take into consideration, however, that an empirical analysis that takes the above model as its starting point would end up with a different regression specification than those used so far. Estimates of markups in the literature usually start from a representation of an aggregate technology like

$$
\hat{Y}=\hat{A}+(\alpha+\beta) \hat{K}+\frac{1}{1-\eta^{-1}} \frac{w^{L} L}{p Y}[\hat{L}-\hat{K}],
$$

where again $\hat{z} \equiv d z / z, \alpha$ and $\beta$ are the output elasticities of capital $K$ and labour $L$, respectively, $A$ is total factor productivity and $\left(1-\eta^{-1}\right)^{-1}$ is the markup (e.g. eq. (5.26) in Hall, 1990, or eq. (2) in Basu and Fernald, 1997). The degree of increasing returns is given by $\alpha+\beta$.

In order to get a corresponding equation for our case, one would have to imagine an extension of the above model to allow for capital and (given that there are no observations on $L$ and $H$ ) merge all workers in one group $L$. The starting point for regressions would then be

$$
\hat{x}=\hat{A}+\hat{K}_{x}+\frac{1}{1-\eta^{-1}} \frac{w^{L} L_{x}}{p x}\left[\hat{L}_{x}-\hat{K}_{x}\right] .
$$

The crucial difference to (26) consists in the expression $w^{L} L_{x} /(p x)$. Instead of the share of total labour in output, $w^{L} L /(p Y)$, this equation contains only the share of labour used in production (i.e. only labour causing variable cost, and not labour being employed in administrative activities and causing fixed cost). If the prediction of the above model on shrinking markups is to be tested, this should therefore be taken into consideration. If firms become slimmer in the real world and $w^{L} L_{x} /(p x)$ in (27) increases, the markup $\left(1-\eta^{-1}\right)^{-1}$ would have to decrease.

Summarizing, future work on markups should take fixed cost and the possibility of variable importance of fixed cost relative to total cost or output 
into account. When this is done, insight about the empirical relevance of the above theoretical model can be gained.

\section{Conclusion}

We have analyzed a model with Cournot competition and free entry and exit where production requires a fixed amount of administration services. The number of firms active in such an economy and the markup of firms decreases when competition rises. When international integration takes place, competition increases and some domestic and foreign firms exit the market. The number of firms producing in an integrated world economy is therefore lower than the sum of the number of firms producing in autarcic economies. Nevertheless, it is higher than the number of firms in each country in autarky. This is the competition increasing effect of integration.

More international competition leading to shrinking markups implies an expansion of plant size for surviving firms. Assuming that the production technology is more skill intensive than the administration technology, these factor movements lead to a decrease in skill intensity in all sectors and therefore an increase of factor rewards for skills. When integration takes place between countries of identical factor endowment, integration does not affect relative prices by trade flows. Nevertheless, relative factor rewards change.

Measuring factor rewards in real terms, integration implies an increase in real rewards for skilled individuals, real wages for less-skilled may fall or rise, depending on the degree of domestic distortions before opening up to trade. If domestic distortions were weak (e.g. in a large country with small markups), more competition implies a real decrease in wages. If domestic distortions were strong (in a country with high markups), integration leads to a considerable increase in the number of firms and therefore to a strong reduction of the distortion. This positive effect can outweigh the negative effect of losses of wages relative to skills caused by factor relocation from administration to production. Summarizing, more international competition has a lifting-all-boats effect if the increase in competition is sufficiently large. If not, more international competition implies that certain factors of production loose in real terms.

When calibrating the model, it turned out that the increase in withingroup wage inequality in the US from 1963 to 1995 can be attributed both to economic growth and integration in the world economy. Given our theoretical analysis, however, integration in the world economy plays a substantially larger role than economic growth in explaining the increase in wage inequality. 


\section{$7 \quad$ Appendix ${ }^{15}$}

\subsection{Some notation}

We define a matrix $\lambda$ that shows the fraction of factors used in the production of the consumption good and in administration services,

$$
\lambda=\left[\begin{array}{cc}
\lambda_{l x} & \lambda_{l m} \\
\lambda_{h x} & \lambda_{h m}
\end{array}\right] \equiv\left[\begin{array}{cc}
a_{l x} n x / L & a_{l m} n \bar{m} / L \\
a_{h x} n x / H & a_{h m} n \bar{m} / H
\end{array}\right]
$$

Rows in this matrix add to unity,

$$
\lambda_{i x}+\lambda_{i m}=1, \quad i=l, h .
$$

The determinant of $\lambda$ is negative if and only if the production is more skill intensive than administration,

$$
|\lambda|=\frac{n x n \bar{m}}{L H}\left(a_{l x} a_{h m}-a_{h x} a_{l m}\right) \lessgtr 0 \Leftrightarrow \rho_{x} \equiv \frac{a_{h x}}{a_{l x}} \gtrless \rho_{m} \equiv \frac{a_{h m}}{a_{l m}} .
$$

Using (29), the determinant of $\lambda$ can be written as

$$
|\lambda|=\lambda_{l x}-\lambda_{h x}
$$

The matrix $\theta$ denoting the share of the return attributed to the factors in the activities can be defined as

$$
\theta=\left[\begin{array}{cc}
\theta_{l x} & \theta_{h x} \\
\theta_{l m} & \theta_{h m}
\end{array}\right] \equiv\left[\begin{array}{cc}
\mu a_{l x} w_{L} / p_{x} & \mu a_{h x} w_{H} / p_{x} \\
a_{l m} w_{L} & a_{h m} w_{H}
\end{array}\right] .
$$

Again, the rows of the matrix $\theta$ add to one, i.e.

$$
\theta_{l j}+\theta_{h j}=1, \quad j=x, m .
$$

The determinant of $\theta$ is negative if the same condition as in (30) is met,

$$
|\theta| \lessgtr 0 \quad \Leftrightarrow \quad \rho_{x} \gtrless \rho_{m} .
$$

Using (33), the determinant of $\theta$ reads

$$
|\theta|=\theta_{l x}-\theta_{l m}
$$

\footnotetext{
${ }^{15}$ An additional appendix with further derivations is available upon request.
} 


\subsection{Differing skill richness}

This appendix looks at distributional effects of integrating with an economy that has a different skilled to less-skilled labour ratio than the economy under consideration. In terms of our reduced form (22), this means that we now allow for changes in $\kappa$ as well. In what follows, we assume factor price equalization. Differences in skill endowment of trading economies should therefore be not too large.

The traditional effect is summarized in the following generalization of proposition 4 which directly follows from (22):

Proposition 8 Human capital rewards $w_{H}$ rise relative to wages $w_{L}$ ceteris paribus whenever skill richness $\kappa$ falls,

$$
\hat{w}_{H}-\hat{w}_{L}=-\frac{1}{|J|}\left[\mu|\lambda| \hat{s}+\left(1+\mu \lambda_{l x}\right) \hat{\kappa}\right] .
$$

Understanding this equation is straightforward: integration implies relative gains of skills due to the effect studied before. Integration with a skillpoor country, i.e. $\hat{\kappa}<0$, makes skills more scarce and skilled individuals gain further. Relative skill gains can be (over-) compensated if the country integrates with a skill-rich country, i.e. for $\hat{\kappa}>0$.

More important for policy discussions are the effects on real factor rewards. We can repeat the results of proposition 5 :

Proposition 9 The factor of production that gains relative to the other factor, also gains in real terms,

$$
\begin{aligned}
& \hat{w}_{H}-\hat{p}_{x}=\theta_{l x}\left(\hat{w}_{H}-\hat{w}_{L}\right)+\frac{\hat{n}}{n-1} . \\
& \hat{w}_{L}-\hat{p}_{x}=\theta_{h x}\left(\hat{w}_{L}-\hat{w}_{H}\right)+\frac{\hat{n}}{n-1} .
\end{aligned}
$$

Proof. These expressions were derived in (24) and the proof of proposition 5 .

The lifting all boats effect $\hat{n} /(n-1)$ is present in both equations: Whether a country starts trading with another country that has more or less skilled individuals relative to its labour endowment, an integrated world economy always has more resources than a country in autarky. As a consequence, the number of firms under integration is larger, $\hat{n} /(n-1)>0$, and competition therefore fiercer. Both factors of production gain from this effect. Clearly, the factor that gains in relative terms also gains in real terms, as both expressions in (37) or (38) would then be positive. 
The potential loss in real wages of a factor of production induced by changes in relative endowment $\kappa$ therefore works entirely through the relativewage channel (36) and not through the pro-competitive effect. This also makes clear why proposition 6 remains unchanged, despite changes in $\kappa$.

One could now analyze the extreme case where an increase in $L$, keeping $H$ constant, i.e. taking up trade with a country that is very labour rich, leads to increases in real wages of unskilled workers. It can be shown and it is intuitively clear that the number of firms increases as long as the resource base of an integrated world economy rises. Hence, workers benefit from more competition among firms. This effect is not strong enough, however, to balance the decrease in wages due to more labor supply. Summarizing, the endowment effect of more labour supply is always stronger than the induced competition effect and real factor rewards for labour fall.

\section{References}

[1] Acemoglu, D. (2002), Technical Change, Inequality, and the Labor Market. Journal of Economic Literature 40: 7-72.

[2] Aghion, P., 2002, Schumpeterian Growth Theory and the Dynamics of Income Inequality. Econometrica 70: 855 - 882.

[3] Altug, S. and A. Filiztekin (2002), Scale Effects, Time-Varying Markups, and the Cyclical Behaviour of Primal and Dual Productivity. Applied Economics 34: 1687 - 1702.

[4] Basu S. and J. G. Fernald (1995), Are apparent productive spillovers a figment of specification error? Journal of Monetary Economics 36: 165 - 188 .

[5] Bhagwati, J. N. (1994), Free trade: Old and new challenges. Economic Journal 104: 231-246.

[6] Caroli, E. and J. van Reenen (2001), Skill-biased organizational change? Evidence from a Panel of British and French Establishments. Quarterly Journal of Economics 116: 1449 - 1492.

[7] Dixit, A. K. (1984), International trade policy for oligopolistic industries. Economic Journal 94: 1S-16S.

[8] Eaton, J. and G. M. Grossman (1986), Optimal trade and industrial policy under oligopoly. Quarterly Journal of Economics 101: 383-406. 
[9] Feenstra, R. C., 2001, Special issue on trade and wages. Journal of International Economics 54: 1 - 3.

[10] Flam, H. and E. Helpman (1987), Industrial policy under monopolistic competition. Journal of International Economics 22: 79-102.

[11] Galor, O. and Moav, O. (2000), Ability-Biased Technological Transition, Wage Inequality, and Economic Growth. Quarterly Journal of Economics 115: 469 - 497.

[12] Hall, R. E. (1988), The Relation between Price and Marginal Cost in U.S. Industry. Journal of Political Economy 96: 921 - 947.

[13] Hall, R. E. (1990), Invariance Properties of Solow's Productivity Residual. In Diamond, P. (ed.) Growth, Productivity, Unemployment. MIT Press.

[14] Johnson, G. and F. Stafford (1999), The Labor Market Implications of International Trade. In O. Ashenfelter and D. Card (eds.), Handbook of Labor Economics, vol. 3b. North Holland.

[15] Jones, R. W. (1965), The structure of simple general equilibrium models. Journal of Political Economy 73: 557-572.

[16] Katz, L. and D. Autor (1999), Changes in the Wage Structure and Earnings Inequality. In O. Ashenfelter and D. Card (eds.), Handbook of Labor Economics, vol. 3a. North Holland.

[17] Krugman, P. (2000), Technology, trade and factor prices. Journal of International Economics 50: 51-71.

[18] Lindbeck, A. and D. Snower (1996), Reorganization of Firms and Labor Market Inequality. American Economic Review Papers and Proceedings 86: $315-321$.

[19] Markusen, J. R., Melvin, J. R., Kaempfer W. H. and Maskus, K. E. (1995), International trade. Theory and evidence, McGraw-Hill.

[20] Neary, J. P. (2002), Foreign competition and wage inequality. Review of International Economics, 10: 680-693.

[21] Roeger, W. (1995), Can Imperfect Competition Explain the Difference between Primal and Dual Productivity Measures? Estimates for U.S. Manufacturing. Journal of Political Economy 103: 316 - 330. 
[22] Ruffin, R. J. (2003), Oligopoly and trade: what, how much, and for whom? Journal of International Economics 60: 315-335.

[23] Venables, A. J. (1985), Trade and trade policy with imperfect competition: The case of identical products and free entry. Journal of International Economics 19: 1-20.

[24] Wälde, K. (2000), Egalitarian and Elitist Education Systems as the Basis for International Differences in Wage Inequality. European Journal of Political Economy 16: 445-468. 


\section{CESifo Working Paper Series}

(for full list see www.cesifo.de)

1189 Robert J. Gary-Bobo and Alain Trannoy, Efficient Tuition Fees, Examinations, and Subsidies, May 2004

1190 Saku Aura and Gregory D. Hess, What's in a Name?, May 2004

1191 Sjur Didrik Flåm and Yuri Ermoliev, Investment Uncertainty, and Production Games, May 2004

1192 Yin-Wong Cheung and Jude Yuen, The Suitability of a Greater China Currency Union, May 2004

1193 Inés Macho-Stadler and David Pérez-Castrillo, Optimal Enforcement Policy and Firms' Emissions and Compliance with Environmental Taxes, May 2004

1194 Paul De Grauwe and Marianna Grimaldi, Bubbles and Crashes in a Behavioural Finance Model, May 2004

1195 Michel Berne and Gérard Pogorel, Privatization Experiences in France, May 2004

1196 Andrea Galeotti and José Luis Moraga-González, A Model of Strategic Targeted Advertising, May 2004

1197 Hans Gersbach and Hans Haller, When Inefficiency Begets Efficiency, May 2004

1198 Saku Aura, Estate and Capital Gains Taxation: Efficiency and Political Economy Consideration, May 2004

1199 Sandra Waller and Jakob de Haan, Credibility and Transparency of Central Banks: New Results Based on Ifo's World Economicy Survey, May 2004

1200 Henk C. Kranendonk, Jan Bonenkamp, and Johan P. Verbruggen, A Leading Indicator for the Dutch Economy - Methodological and Empirical Revision of the CPB System, May 2004

1201 Michael Ehrmann, Firm Size and Monetary Policy Transmission - Evidence from German Business Survey Data, May 2004

1202 Thomas A. Knetsch, Evaluating the German Inventory Cycle - Using Data from the Ifo Business Survey, May 2004

1203 Stefan Mittnik and Peter Zadrozny, Forecasting Quarterly German GDP at Monthly Intervals Using Monthly IFO Business Conditions Data, May 2004 
1204 Elmer Sterken, The Role of the IFO Business Climate Indicator and Asset Prices in German Monetary Policy, May 2004

1205 Jan Jacobs and Jan-Egbert Sturm, Do Ifo Indicators Help Explain Revisions in German Industrial Production?, May 2004

1206 Ulrich Woitek, Real Wages and Business Cycle Asymmetries, May 2004

1207 Burkhard Heer and Alfred Maußner, Computation of Business Cycle Models: A Comparison of Numerical Methods, June 2004

1208 Costas Hadjiyiannis, Panos Hatzipanayotou, and Michael S. Michael, Pollution and Capital Tax Competition within a Regional Block, June 2004

1209 Stephan Klasen and Thorsten Nestmann, Population, Population Density, and Technological Change, June 2004

1210 Wolfgang Ochel, Welfare Time Limits in the United States - Experiences with a New Welfare-to-Work Approach, June 2004

1211 Luis H. R. Alvarez and Erkki Koskela, Taxation and Rotation Age under Stochastic Forest Stand Value, June 2004

1212 Bernard M. S. van Praag, The Connexion Between Old and New Approaches to Financial Satisfaction, June 2004

1213 Hendrik Hakenes and Martin Peitz, Selling Reputation When Going out of Business, June 2004

1214 Heikki Oksanen, Public Pensions in the National Accounts and Public Finance Targets, June 2004

1215 Ernst Fehr, Alexander Klein, and Klaus M. Schmidt, Contracts, Fairness, and Incentives, June 2004

1216 Amihai Glazer, Vesa Kanniainen, and Panu Poutvaara, Initial Luck, Status-Seeking and Snowballs Lead to Corporate Success and Failure, June 2004

1217 Bum J. Kim and Harris Schlesinger, Adverse Selection in an Insurance Market with Government-Guaranteed Subsistence Levels, June 2004

1218 Armin Falk, Charitable Giving as a Gift Exchange - Evidence from a Field Experiment, June 2004

1219 Rainer Niemann, Asymmetric Taxation and Cross-Border Investment Decisions, June 2004

1220 Christian Holzner, Volker Meier, and Martin Werding, Time Limits on Welfare Use under Involuntary Unemployment, June 2004 
1221 Michiel Evers, Ruud A. de Mooij, and Herman R. J. Vollebergh, Tax Competition under Minimum Rates: The Case of European Diesel Excises, June 2004

1222 S. Brock Blomberg and Gregory D. Hess, How Much Does Violence Tax Trade?, June 2004

1223 Josse Delfgaauw and Robert Dur, Incentives and Workers' Motivation in the Public Sector, June 2004

1224 Paul De Grauwe and Cláudia Costa Storti, The Effects of Monetary Policy: A MetaAnalysis, June 2004

1225 Volker Grossmann, How to Promote R\&D-based Growth? Public Education Expenditure on Scientists and Engineers versus R\&D Subsidies, June 2004

1226 Bart Cockx and Jean Ries, The Exhaustion of Unemployment Benefits in Belgium. Does it Enhance the Probability of Employment?, June 2004

1227 Bertil Holmlund, Sickness Absence and Search Unemployment, June 2004

1228 Klaas J. Beniers and Robert Dur, Politicians' Motivation, Political Culture, and Electoral Competition, June 2004

1229 M. Hashem Pesaran, General Diagnostic Tests for Cross Section Dependence in Panels, July 2004

1230 Wladimir Raymond, Pierre Mohnen, Franz Palm, and Sybrand Schim van der Loeff, An Empirically-Based Taxonomy of Dutch Manufacturing: Innovation Policy Implications, July 2004

1231 Stefan Homburg, A New Approach to Optimal Commodity Taxation, July 2004

1232 Lorenzo Cappellari and Stephen P. Jenkins, Modelling Low Pay Transition Probabilities, Accounting for Panel Attrition, Non-Response, and Initial Conditions, July 2004

1233 Cheng Hsiao and M. Hashem Pesaran, Random Coefficient Panel Data Models, July 2004

1234 Frederick van der Ploeg, The Welfare State, Redistribution and the Economy, Reciprocal Altruism, Consumer Rivalry and Second Best, July 2004

1235 Thomas Fuchs and Ludger Woessmann, What Accounts for International Differences in Student Performance? A Re-Examination Using PISA Data, July 2004

1236 Pascalis Raimondos-Møller and Alan D. Woodland, Measuring Tax Efficiency: A Tax Optimality Index, July 2004

1237 M. Hashem Pesaran, Davide Pettenuzzo, and Allan Timmermann, Forecasting Time Series Subject to Multiple Structural Breaks, July 2004 
1238 Panu Poutvaara and Andreas Wagener, The Invisible Hand Plays Dice: Eventualities in Religious Markets, July 2004

1239 Eckhard Janeba, Moral Federalism, July 2004

1240 Robert S. Chirinko, Steven M. Fazzari, and Andrew P. Meyer, That Elusive Elasticity: A Long-Panel Approach to Estimating the Capital-Labor Substitution Elasticity, July 2004

1241 Hans Jarle Kind, Karen Helene Midelfart, Guttorm Schjelderup, Corporate Tax Systems, Multinational Enterprises, and Economic Integration, July 2004

1242 Vankatesh Bala and Ngo Van Long, International Trade and Cultural Diversity: A Model of Preference Selection, July 2004

1243 Wolfgang Eggert and Alfons J. Weichenrieder, On the Economics of Bottle Deposits, July 2004

1244 Sören Blomquist and Vidar Christiansen, Taxation and Heterogeneous Preferences, July 2004

1245 Rafael Lalive and Alois Stutzer, Approval of Equal Rights and Gender Differences in Well-Being, July 2004

1246 Paolo M. Panteghini, Wide vs. Narrow Tax Bases under Optimal Investment Timing, July 2004

1247 Marika Karanassou, Hector Sala, and Dennis J. Snower, Unemployment in the European Union: Institutions, Prices, and Growth, July 2004

1248 Engin Dalgic and Ngo Van Long, Corrupt Local Government as Resource Farmers: The Helping Hand and the Grabbing Hand, July 2004

1249 Francesco Giavazzi and Guido Tabellini, Economic and Political Liberalizations, July 2004

1250 Yin-Wong Cheung and Jude Yuen, An Output Perspective on a Northeast Asia Currency Union, August 2004

1251 Ralf Elsas, Frank Heinemann, and Marcel Tyrell, Multiple but Asymmetric Bank Financing: The Case of Relationship Lending, August 2004

1252 Steinar Holden, Wage Formation under Low Inflation, August 2004

1253 Ngo Van Long and Gerhard Sorger, Insecure Property Rights and Growth: The Roles of Appropriation Costs, Wealth Effects, and Heterogeneity, August 2004

1254 Klaus Wälde and Pia Weiß, International Competition, Slim Firms and Wage Inequality, August 2004 